\title{
"I've got a sheep with three legs if anybody wants it?": re-visioning the rural economy
}

\author{
Andy Crabtree ${ }^{1} \cdot$ Alan Chamberlain $^{1} \cdot$ Stela Valchovska $^{1} \cdot$ Mark Davies $^{1} \cdot$ \\ Kevin Glover $^{1} \cdot$ Chris Greenhalgh $^{1}$
}

Received: 14 April 2015/Accepted: 19 November 2015/Published online: 7 December 2015

(c) The Author(s) 2015. This article is published with open access at Springerlink.com

\begin{abstract}
This paper reports on a study of 4CG, a cooperative enterprise located in rural Wales. 4CG operates for the good of the local economy and seeks to diversify its commercial portfolio through the creation of an online shop retailing goods and services from local suppliers. The paper compliments prior field studies focusing on rural enterprise and the challenges posed by this category of business for IT support. The current study is motivated by 4CG's interest in setting up a local online shop and explicates the organisational issues that this venture turns upon and elaborates for broader sustainability agendas.
\end{abstract}

\section{Introduction}

Local online shopping cooperatives-i.e. multiple traders located in a small geographical area operating under the auspices of a single online identity - are springing up left, right and centre, particularly in rural contexts where food

Alan Chamberlain

Alan.Chamberlain@nottingham.ac.uk

Andy Crabtree

Andy.Crabtree@nottingham.ac.uk

Stela Valchovska

Stela.Valchovska@nottingham.ac.uk

Mark Davies

Mark.Davies@nottingham.ac.uk

Kevin Glover

Kevin.Glover@nottingham.ac.uk

Chris Greenhalgh

Chris.Greenhalgh@nottingham.ac.uk

1 School of Computer Science, University of Nottingham, Nottingham, UK producers and artisans are banding together and exploiting online solutions to enhance their businesses. A cursory search of the Internet with terms such as 'online farm food collective' reveals a multitude of local initiatives spread across the globe, or the westernised part of it at least. The turn to the local is mirrored on a broader scale by online solutions such as Milo or Amazon's 'Local' online shopping brand, and IBM [16] predicts that 'buying local will beat online' in the not too distant future. Evidently there is increasingly broad interest in the local as a key factor in consumers' decision-making.

This paper sets aside corporate efforts to trade on the local. It focuses instead on grass-roots initiatives that seek to leverage the digital to add value to geographically bounded communities of producers, retailers and consumers. We adopt this particular perspective because it is employed by the people in our study, who seek to develop an online shop to support local enterprise. Their orientation to the local is possessed of some unique characteristics and challenges. Key among these is the need to assemble and sustain a collective identity and coherent service provision on an entirely different level of scale. We are dealing, then, not with the global dressed up as the local, but the local as a thing that is in a great many respects available just here, for just these people, in just this place, at just this time.

The aim here is not to scale up. As prior studies have elaborated [7], not all businesses want to do this. On the contrary, many small and micro-enterprises avoid scaling up and seek instead to 'make a decent living' along with a contribution to the local communities they are part of and whose well-being they help and want to help sustain. In turning to online shopping, they do not rule out trading further afield, or the sale of generally available goods, but this is not their primary concern. This paper seeks to understand what makes this kind of local endeavour tick 
and, in doing so, to elaborate 'what keeps the roof on' the online shop-what holds the enterprise up as it were and drives the adoption of technology-as trader collectives turn to online solutions in a bid to help them make a living locally.

Our study suggests that there is a great deal more to setting up an online shop that configuring the underlying technology. Key to the endeavour is the specification and configuration of an enterprise model, which the technology will have to support. Our study reveals that this turns upon defining the scope and function of an online shop, working out the logistics of delivery and supply, costing the operation, identify and handling risks, and engaging the local community, and that these issues are themselves shaped by an underlying concern with sustainability and the 're-visioning of consumption' [12]. The re-visioning turns upon reworking the relationship between the global and the local, formulating strategies for reconfiguring the global and the parochial to add local value, exploiting manifold expertise to delineate stakeholder relationships and value chains, and engaging the local community to create the necessary context in which the reconfiguration can take place, all of which trades on putting sustainability first and making technology answerable to it.

\section{Methodology}

The question we pose as to 'what keeps the roof on' the local online shop-what holds the enterprise up and drives the adoption of technology-is motivated in many respects by long-standing ethnographic interest in the 'work to make technology work' (see, for example, [13]. This methodological interest is also spoken about in terms of the 'invisible work' involved constructing technologies and putting them to use [21]. It has its roots in Harold Garfinkel's Studies in Ethnomethodology [9] and the mundane (taken for granted and largely ignored) work that people must do to construct a technology and get it to work (any kind of technology, not just digital). Accompanying this is a disciplinary interest in the work's sociological character, particularly its 'organisational' character. In asking 'what keeps the roof on' the local online shop, we are therefore asking two interrelated questions:

- What work does technology adoption turn upon?

- What organisational characteristics does the work possess?

We consider these questions with respect to the 'occasioning' of a local online cooperative shop, which provides ready insight into the work and its organisation from a practical rather than a theoretical viewpoint $[2,23]$. The occasioning was done by $4 \mathrm{CG}$, which has been participating in our fieldwork activities since late 2012 . $4 \mathrm{CG}$ is concerned with a broad range of issues involved the sustainable development of the local economy. Our engagement with 4CG has involved a range of stakeholders, including members of the board and local businesses, in an effort to understand something of the challenges that confront systems design for rural enterprise in a developed context.

The fieldwork approach might be called 'classical' insofar as it makes little use of technology. Interviews and workshops were occasionally recorded on audio, but we have largely relied on the immersion of two fieldworkers in the setting and the development of local knowledge, which has largely been documented in field notes. Both fieldworkers have been active in the field for two years. One of them focused very specifically on 4CG, engaging in periodic visits (approximately quarterly) to understand through observation and informal interview the organisation's entrepreneurial character and its approach to developing the local economy.

The other fieldworker was embedded in the field. Living near to the fieldsite and visiting it on a regular basis (monthly certainly and frequently on a weekly basis), the fieldworker has become a 'familiar face' and 'trusted intermediary'. This has enabled the engagement of a broad range of community stakeholders (including local businesses, customers, councillors, and regional development agencies) in our research [4]. The fieldworker has also conducted observational studies of local enterprises [7] and coordinated meetings between interested stakeholders and our own development team to explore potential design opportunities. This body of fieldwork underpins the work reported here, which focuses on two workshops held by 4CG's board members in 2014 dedicated to exploring the development of the local online shop.

The workshops were recorded on audio and analysed with respect to the 'mundane reasoning' [19] manifest in the board members' discussions. In contrast to conversation analysis, which focuses on the mechanics of talk [20], analysis here focuses on what is being done in the course of talking [17]. The aim is to identify 'work's things' [10]i.e. the objects of mundane reasoning made visible in the conversational topics being 'worked on' and 'worked up' over the course of the board members' conversation. Analysis consists, then, in a close examination of the board members' talk and identification of the 'endogenous' topics occupying their discussions, which is to say that the topics are defined by parties to the conversation, not by us [11]. Presentation of the results involves the use of conversational vignettes to detail and elaborate work's things as given in participants' talk. This analysis of work's things reveals a host of organisational issues key to involved constructing the technology and putting it to use. 


\section{4CG}

Cymdeithas Cynnal a Cefnogi Cefn Gwlad-the Society to Sustain and Support the Rural Countryside or $4 \mathrm{CG}$-is a cooperative venture located in the small town of Cardigan in Wales [1]. By 'cooperative venture' we mean it is a legally defined enterprise registered under the Industrial and Provident Societies Act 1965 [18]. It is a special kind of enterprise in the UK that it is and has to be cooperatively owned by its members and it must operate on the basis of 'one member, one vote' [14].

The first ever recorded cooperative was created in Fenwick, Scotland, in March 1761, when a group of local weavers came together to form the Fenwick Weavers' Society ... From these humble beginnings, the cooperative movement has expanded exponentially. In the UK alone, cooperative society membership has increased from 100,000 in 1863, 4 million in 1918 , to over 15 million in 2013. (HM Treasury [15] )

Co-operatives UK estimates that over one billion people worldwide have a stake in cooperative enterprises, with an annual turnover exceeding one trillion dollars (Co-operatives UK [6]. Cooperative enterprises may operate for the benefit of their members or they may operate for the benefit of the local community, in which case they are classified as a community benefit society or 'bencom'. Bencoms must, by legal requirement, be run for the benefit of people who are not members of the cooperative. Examples of bencoms include retail cooperatives, sports clubs, housing and community associations, and credit unions. Bencoms are subject to charity law, which means in this particular case that the UK's 'taxman' HMRC decides whether or not they are eligible for tax relief. Good reasons for granting it include redevelopment, regeneration and community housing projects [5].

4CG was created in 2010 by six local entrepreneurs to foster redevelopment and regeneration in and around Cardigan. Share capital has been raised through broad community participation. In the three and half years since 4CG was established, it has come to be supported by over 700 shareholders holding over 1400 shares between them with a total investment in excess of $£ 280,000$. Shares cost $£ 200$ each, and personal shareholding is capped at the maximum UK subscription limit of $£ 20,000$. Prospective shareholders unable to raise the money to buy shares outright have been offered financial support by the local credit union. This has resulted in a relatively large number of shareholders who mostly own one or two shares and represent the interests of a substantial part of the Cardigan community (Cardigan has a population of 4000).
4CG was and is motivated by the need to enhance the ongoing viability of the town. As one of the cooperative's founding members puts it,

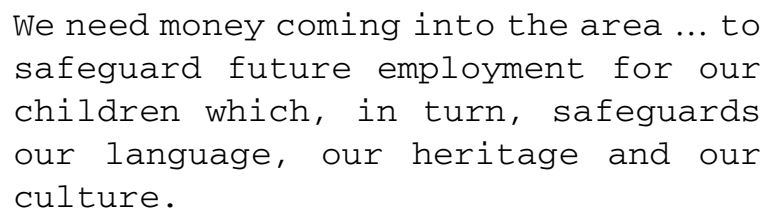

The cooperative is not driven by ordinary commercial motives then, but is concerned to enrich the local area through the development of enterprises that directly benefit the local community. By way of illuminating what is at stake here, members of the cooperative and the broader populace mounted an unsuccessful campaign to reject a planning proposal for the building of (another) national chain supermarket (or large grocery store) in the town. As a member of the cooperative's board of directors puts it,

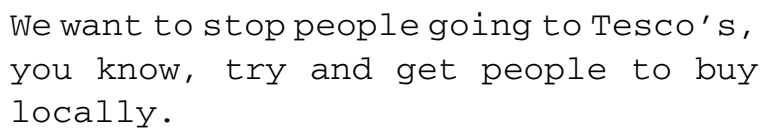

Despite failing to block the proposed development, there is broad interest among the townsfolk to develop alternatives that add and retain value within the local community, and 4CG has started to develop a number of enterprise initiatives to enhance the local economy.

\subsection{The online cooperative shop}

The idea of developing an online cooperative shop is one such initiative, and that 4CG see great potential value in. An important part of the mix here is the motivation for creating an online shop. While there has been a broad turn to online shopping in society at large, it is the local effects of this that motivate the cooperative's turn to the digital. As one of the board members puts it,

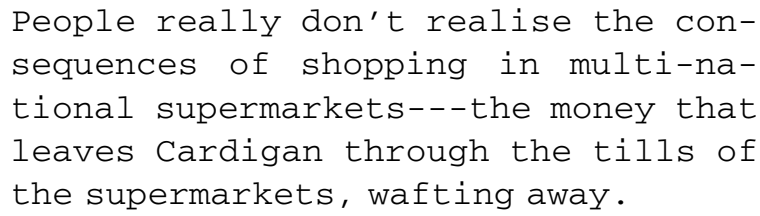

The online supermarket or grocery store is just as much a source of this 'wafting away' of money from the local economy as the physical superstore, and countering this is a key driver motivating the creation of the local online cooperative shop:

If we can ... just get people to realise
that the future of this town depends on
.. getting the money to stay 
circulating in our local economy ... not helping the Cayman Islands.

One of the key problems confronting the local online shop revolves around defining what the local actually is. A matter that vexed the board members at the outset of their discussions:

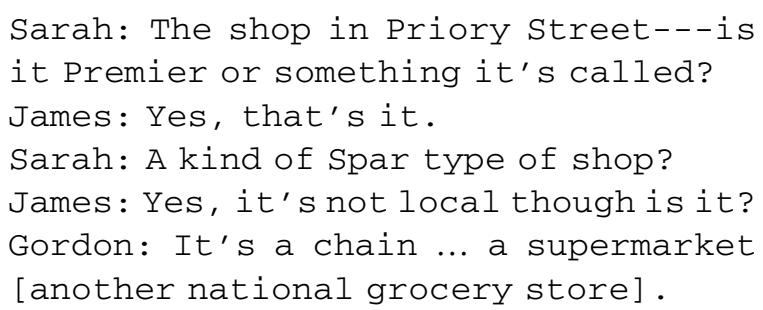

Outlets for national chains are not defined as local then, but what about goods and produce stocked by shops that are considered to be local? Things like baked beans or washing powder or many of the other commonplace goods that can be found in grocery stores large or small across the country:

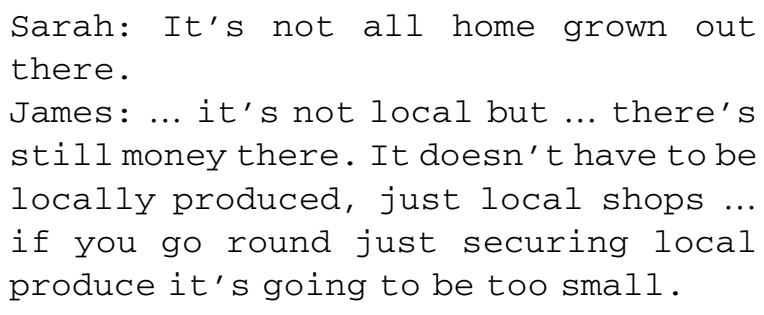

So generally available goods sold by local shops are acceptable, indeed being able to supply them is seen as critical to the endeavour. It is not the origins of the goods per se that matters, then, but who makes profit on them and where that profit essentially resides: in the local economy rather than 'the Cayman Islands'. So what is local? Any enterprise whose profit is principally retained in and around the town. This does not mean that multinational businesses do not benefit, but it does mean that more money circulates within the area.

The turn towards online shopping is also motivated by the perceived value that local trade can offer the consumer:

Susan: ... they'd have a choice of not one butcher, but two butchers', three bakers ...

Sarah: It's the scale of what we offer here...

James: Yes ... if we look at our floor space, shop space, it's bigger than Tesco.

Added value is not only construed of in terms of choice, it also turns on matters of quality and cost:
William: I mean Glebelands now, their vegetables are cheaper than Aldi and people are actually travelling to st Dogmael's to get this stuff because it's good produce and it's actually cheaper ... prices dictate to people at the end of the day.

Sarah: I think people will look at their total shopping basket price ... you could pay more for toilet roll [but] you're getting your kale ten pence cheaper ... counterbalanced by the fact that I'm getting my fresh veg and my fresh meat from local suppliers.

James: What about the bread then in Bedwyn---compared to the bread up in Aldi's?

Susan: You really can't compare--that's something you have to pay extra for---the bread in the supermarkets is disgusting .

Choice, cost and quality are perceived by the board members to be the hallmark of the local and key drivers for shopping locally. They are offset, however, by convenience:

William: People vote with their feet; at the end of the day it comes down to the price.

James: Yes but it's not as simple because you don't shop in Tesco because it's cheaper, you do it because you--convenience---it's more than cash, seven days a week, $24 / 7$... a lot of people, you see, are in work nine 'til five and the reason that they don't support is that.

Susan: One of the biggest problems we've got with the High Street, there's no parking there, you can't park outside a shop and run in. Shops that have got parking do much better than the shops that haven't.

James: The whole purpose of Internet shopping is convenience, isn't it?

The online shop is seen as a means of hurdling the convenience barrier that so badly affects local trade (not only in Cardigan), and of capitalising upon the added value offered by local businesses to enhance the local economy. It is one thing to have a motive for developing an online shop, another to actually develop it however. We turn next 
to consider a range of perceived challenges that confront the shop's development.

\section{Development challenges}

Specific challenges confronting the creation of the online shop include defining its scope and function, working out the logistics of delivery and supply, costing the shop, defining risks, and risk management strategies, and engaging the local community. We discuss each of these below. As above, quotes are drawn from board members who attended the workshops (real names are not used, though they do reflect the participant's actual genders).

\subsection{Defining the scope and function of the online shop}

Defining the scope and function of the online shop is in many respects about defining the business model that should be implemented and its purpose. Not surprisingly a range of models were proposed. The first of these represents a simple extension of the existing town market, shifting the market traders online to extend customer access from one day a week. Accompanying this were ideas for speciality boxes and ready meals, all of which were considered to be reasonable starting points but not sufficient in the longer term. The idea of a 'core shop' emerged as an alternative, premised on the recognition that most people routinely buy a core set of things on a regular basis (bread, meat, vegetables, etc.), but again this was seen as problematic:

Susan: The supermarkets have got it right, and if you can't beat them, join them; you have to play them at their own game ... the customer---they expect to get everything they want in one stop, in one place---so if we could offer as much as we can without going completely over the top, you know, all the shopkeepers would jump at the chance.

James: We're talking about our own supermarket, really.

Susan: Yes, the independent republic of $4 \mathrm{CG}$.

James: We could call it CBay. ]

While appealing, nailing down the actual scope of a local online supermarket directly competing with national chains was also problematic:

William: I think the main thing we want to achieve is to help the High Street ... because they're struggling. If we had a delivery-type of system ... and include all the shops on the High street, then at the end of the day we'd be helping them to basically survive.

Sarah: That's definitive, is it? It is for the High Street? Do you mean every single shop? So we' re talking about the butchers and the bakers ...

William: The pharmacies as well, I'd say .

Susan: I think if you take all of the local shops in Cardigan, you know, what else do we need? You' re looking at local chemists, hardware stores, butchers... william: The thing is it's not just limited to the High Street, other people---fishermen---you know...

James: Farmers.

William: Farmers---if somebody wants half a cow.

James: I've got a sheep with only three legs if anybody wants it?

Sarah: I just don't think we've defined what we're trying to do.

William: Well yes, but that's what we're here for, I think.

James: We have to be able to cater for whatever it is people want.

Susan: We need to be able to deliver almost everything.

Gordon: It's a tall order though, isn't it?

Tall order or not, each of the business models proposed was construed of under the same functional auspices: to enhance and not compete with local trade. Whether extending access to the town market and the products it supplies, supporting the core shop or creating a full-blown supermarket, all parties felt it important that whatever model was adopted it should not impact negatively on any of the local traders and producers.

\subsection{Coordinating delivery}

A key issue that occupied the board members in their discussion of the online shop was delivering local products to customers. This was seen to be more than simply a logistical matter, but a primary way in which 4 CG could itself add value to the local economy:

Sarah: I think coordinating deliveries---take that as a starting point--is a good idea actually. What does 4CG 
add to what exists currently? I think coordinating deliveries is quite a good starting point to think about what role the organisation could play.

Coordinating delivery would enable the organisation to act as an intermediary and facilitator to local trade, though of course the questions arose as to just how it should fulfil this role and actually do the delivering? Several mechanisms were proposed and considered, along with a number of practical concerns.

In the first instance 'piggy-backing' on local traders was considered as key means of coordination:

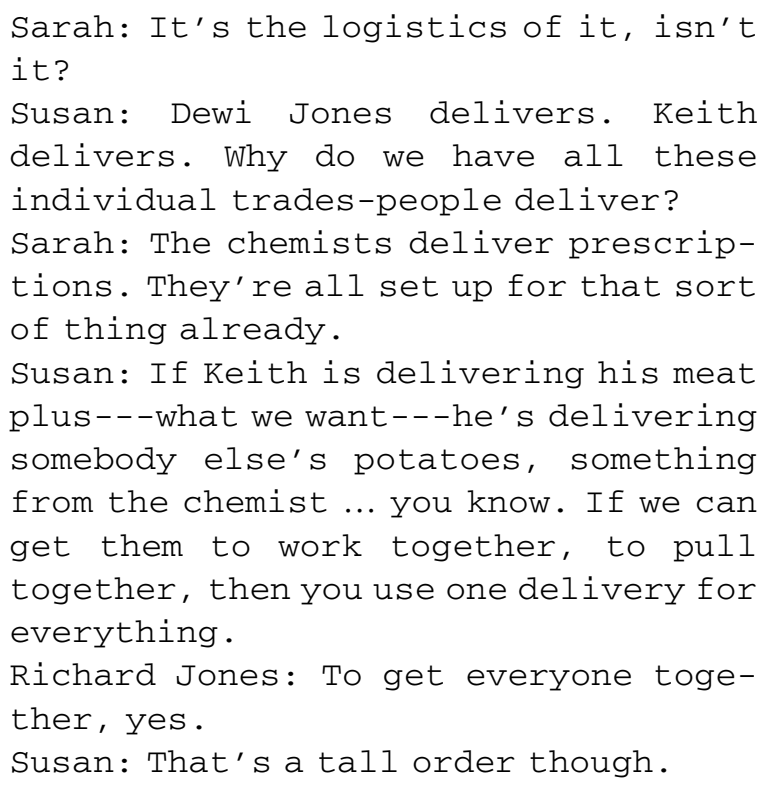

Given the tallness of the order, alternatives were considered including hiring vehicles locally and a do-it-yourself solution. With respect to the costs associated with the latter, of buying and maintaining a vehicle and employing a driver, the idea was also floated of using electric vehicles and setting up the infrastructure to recharge them in order to reduce long term costs.

Then there was the issue of frequency: how often to do delivery? Everyday, three times a week, once a week? There was no clear answer but the dilemma was clear:

William: One of the reasons Pembrokeshire Farmers failed was because they were only delivering once or twice a week ... if you want something normally you need it ... within $24 \mathrm{~h}$.

James: I don't know---if you haven't got toilet paper you want it now ...

Gordon: It's urgent.

Susan: I think that would be above and beyond the call of duty.
So how often to do deliveries? More than once or twice a week, probably within $24 \mathrm{~h}$, but not same day.

Cost was a reoccurring issue in the delivery discussion. A range of potential solutions that revolved around the notion of 'collection points' rather than door-to-door delivery were proposed to mitigate delivery costs. Potential solutions included setting up a central collection point:

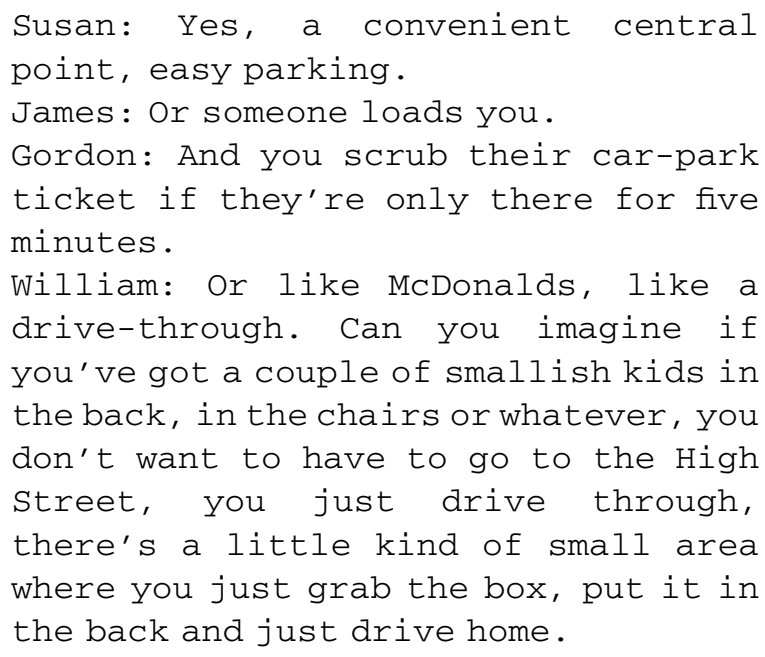

Community satellites were also considered-where deliveries for a group of people would be dropped off at one place for collection-as were post offices and shops in the outlying areas around the town:

William: Instead of delivering to the actual customer ... we deliver to say the local post office and they have a bank of lockers where you have your own locker. So you just deliver it, put it in there, lock it and then the customer just picks it up at his own leisurely time. That would be attractive to the local shop because that in itself brings customers to the shop---and we save money on delivery, we don't have to go round all the houses; so we could make the delivery cost that much cheaper ... In recent years a lot of post offices have shut in rural villages and that might just make the difference to them staying open.

Accompanying and extending this idea was that of the bespoke unit, such as a container, that could be situated alongside rural shops or other venues 'like they do in Canada and Australia' so as to handle anticipated storage problems in village shops, which are typically quite small. This in turn prompted discussion of the delivery boxes: 
Susan: How big is a box of your weekly shop?

Gordon: Well imagine how much you put in a trolley.

Susan: So we'd need a selection of boxes---like the family box, couples, and singles.

It was not just the size of the delivery boxes that was of concern, but food safety was a key issue too:

Sarah: I was just wondering about the freshness of stuff---if you order meat ...

William: It would have to be chilled. Susan: You can get boxes that stay below a certain temperature for $24 \mathrm{~h}---$ even with frozen goods.

James: The only thing is for something that's frozen you need something sealed.

As the above vignettes make clear, delivery is in many and varied ways a challenging matter, especially when consumer choice is entered to the equation and discounts are attached to various methods such as the group shop and personal collection. Nevertheless, coordinating delivery is seen as the key way in which $4 \mathrm{CG}$ can add value to the local economy.

\subsection{Coordinating supply}

Coordinating the supply of goods was also a major discussion topic. This largely revolved around two main means of coordination: traders supplying goods to $4 \mathrm{CG}$ and $4 \mathrm{CG}$ collecting goods from traders. Both were seen to have their pros and cons, and both traded on an underlying vision of the shopping system:

William: The traders ... would ... register their produce, with particular barcodes, online. So they take pictures of their produce---we'd supply barcodes somehow---which they'd put on---the way I would see it is if somebody actually made an order, an email would go to each trader with the actual order and then they would get the barcodes, put them on whatever produce and then box that ready to go. How that box gets down to our stores or our van calls round and picks them up I don't know.

The first posited coordination mechanism would involve 4CG setting up a 'central warehouse', where traders would deposit bar-coded boxes. The perceived advantage of the warehouse was that it provides a store for non-perishable goods:

Susan: We'd have a selection of what they sell in the shops; we'd have it in our warehouse ready to go, with their barcodes on. Say Keith brings down a pallet full of baked beans and they're all bar-coded. Every time someone wants baked beans, right, great, click---well that's credited to his account.

The downside of this solution is the costs that inevitably accompany setting up and running a warehouse:

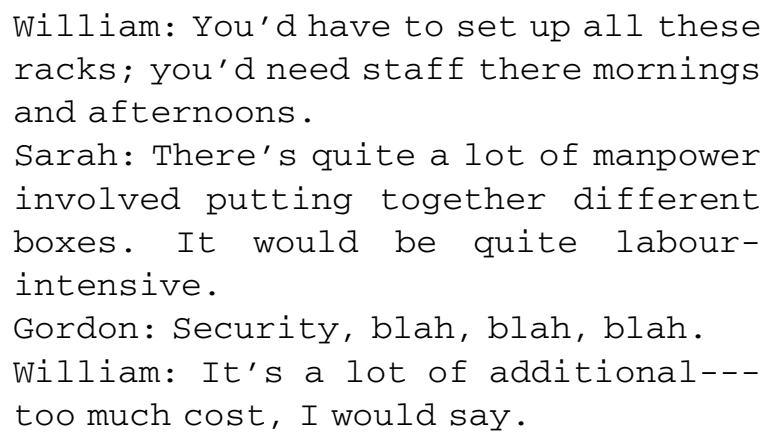

The alternative-collecting from traders-mitigates some of the perceived costs, but not all; a vehicle is required, someone to collect orders, and then there is the problem of actually coordinating collection in an orderly rather than haphazard manner if costs are to be kept under control. Complicating matters here is the distinction between perishable and non-perishable goods, the latter having to be collected on the day of delivery, which suggests that a combination of methods is required.

\subsection{Costs}

Costs, as can be seen above, are a recurrent theme in the board's discussions, and they extend beyond issues to do with delivery and supply. The principle concern about cost, and one that drives various substantive considerations (cost of delivery, cost of supply, etc.) is to do with the sustainability of the proposed venture:

William: It's got to be sustainable, we've got to cover our costs at the end of the day, we can't just live on grass, so whatever the model we come up with--say the delivery vans and employees down here---then it has to be sustainable so the margin we would take from 
each shopper on each produce would cover our costs.

The concern with sustainability manifests itself in various ways, ranging across cost calculations to equipment:

William: We've got to calculate---we haven't even worked out what kind of anticipated figures are. We haven't worked out cost estimations---what the delivery costs are ... the volumes ... how we can deliver it, how many people you need to deliver it, how much admin staff, software back-up support. Calculate the value for that first and then you work out---see the way I see it there would be a transaction for say delivery, to say 4CG because they're doing the delivery, and then your additional costs, and then the rest of the monies would be distributed back to the traders.

Sarah: If we've got to start buying chilled boxes and ...

James: I had a chat with Wynn and he was quoting about $£ 8000$ to $£ 9000$ for a van with a refrigerated compartment inside it.

William: With these kinds of things, see, normally you do market research and find a figure on what percentage of the local population would actually use this service, what's the volume and the value they would actually spend and what percentage of that we would get back, and we could work out then whether that equates to the costs we've got down here.

Anticipated volumes, delivery costs, staff, technical support, transaction charges, hardware and transport costs, etc., all have to be taken into account and calculated before any decision to invest in an online shop can be reached, and cost considerations need to balanced alongside the perceived risks of the enterprise.

\subsection{Risks}

Risk visibly permeated the board's discussions in the constant vying of options and alternatives: which business model to adopt, which delivery mechanisms, which supply mechanisms, etc.? Consideration of each of these substantive issues and more were driven by an inherent sense of risk. They are complemented by concerns with the impact of the proposed venture on the social fabric:

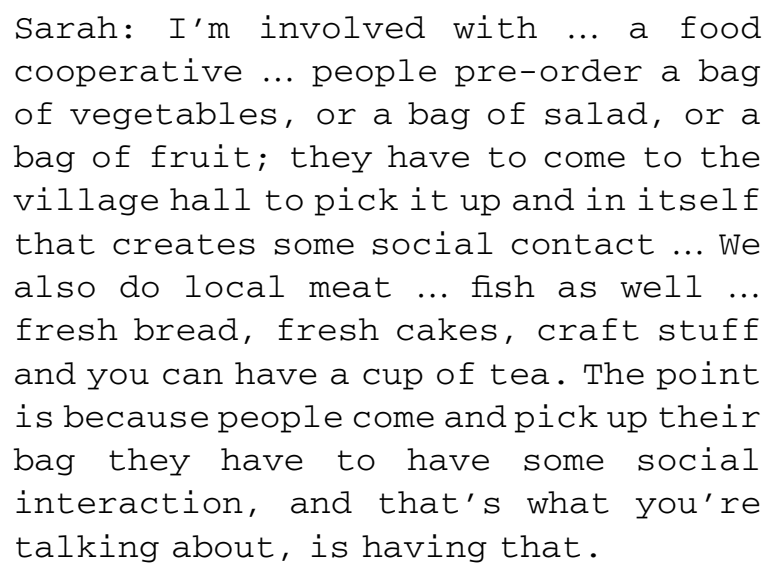

The impact of online shopping on social interaction was manifest in various ways, but it was not felt to be a major risk in itself. As one board member put it, 'you can build up a relationship even if it is over the internet'. More serious were the perceived scope of the online shop and the complex array of challenges involved in federating a broad cohort of independent traders.

A key concern with respect to this was the ability of traders to meet demand. This manifested itself in two ways: one with respect to supply failure (i.e. what happens if a trader doesn't deliver?) and the other with potential underlying causes that could have catastrophic effect:

James: What about volumes? If it's high volumes---is the website going to be able to cope with all these orders coming in? These people at Glebelands [for example], how much are they going to produce? It's going to be first-come, first-served, you know; if this takes off, all the production they can do there will be sold by the end of the week---it's economies of scale.

Williams: I think it goes back to the sustainability thing at the end of the day and you need the volume.

As these two extracts make clear, volume is a tricky matter, a doubled-edged sword. On the one hand, it can be the source of failure due to there being a level of demand that exceeds the volumes local traders can deliver. On the other hand, it can be the source of failure due to there being too little demand and not enough turn over of produce and goods. Striking the balance and managing risk are key. 


\subsection{Risk management}

Risk management revolved around two key issues: market research, and roll-out or deployment strategy for the online shop. Market research covered two areas: understanding just what goods the local shops could provide, and understanding just what services customers would want the online shop to provide. The latter included consideration of who the core customers would be: locals or tourists who, as noted above, are key contributors to the local economy. It was felt that the local cohort was the primary target. A 'visioning day'-i.e. on open day hosted by $4 \mathrm{CG}$-was planned to present ideas for the online shop to the local populace, to be complemented by a questionnaire to assess potential customer buy-in, evaluate proposals, and define how the shop should operate.

The bulk of discussion regarding risk management revolved around roll-out and focused on piloting the online shop. This involved a number of distinct considerations: the initial reach of the shop, the nature of the pilot and the trader and customer cohorts involved. The board members felt it important to constrain roll-out:

Sarah: I think to start it all-singing, all-dancing, straight across the board is not going to be right.

William: We need to keep the model as simple as possible to start with.

James: Define simple.

William: Well a simpler model, I think, is---you have a zone, don't you?

In addition to limiting the reach of the shop, and thereby constraining it to a clearly defined geographical area, piloting the shop was also considered to be an important step to take:

Sarah: You've got to run a trial, I think, first. You can't just jump in.

William: ... maybe just have a fixed customer-base for a period of time, say a month. You only allow say 100 customers to have a look at it, so you're keeping the numbers to a minimum---that allows us time to sort our problems out.

James: Keep it simple to start with and then just see where things go afterwards

Sarah: It might be better to try it for one day a week and make it a Thursday or a Friday when people know what they're going to want for the weekend. Pilot it on a fairly small basis initially ... then see if it's successful and scale it up accordingly.
As the above vignette makes visible, the number of participants, duration and frequency of the pilot are all important ingredients in managing risk.

Defining the trader and customer cohorts matters too:

William: We need about ten traders for this---we need enough choice, but not too much to swamp the system. The one advantage that we have with 4 CG is that ... we have a level of trust, I think, from some on the High Street. So I think if we did start up something I think quite a few of them would trust us enough to give it a go anyway.

While nailing down the trader cohort was relatively unproblematic, defining the customer cohort for the pilot was more of a challenge:

Sarah: I think you need to do a prototype. You need to have it running for a finite period of time with a finite number of people and just say to them look, would you just mind being guinea pigs? You know problems will show up then but they won't kill the project because the people involved will be more tolerant. William: You want people who are tolerant to start off with.

Susan: We could ask the shareholders. If the shareholders think it---if it works well with a few shareholders--we could handpick a few shareholders that would be willing to help us pilot this.

James: You could always do like a PR thing. Like you have it only delivered for one day a week, but then you could say oh because there's been so much we're now going to have to deliver on two days a week.

Susan: It would be quite interesting if we could get somewhere up in Maesglas, you know, there's a big estate at the top of Cardigan---if we could get from five to ten people, families up there, which would just help us pilot this. Ideally we'd have a pocket with about ten families there.

William: On one street or something?

Susan: Definitely one estate where you could pilot this to see how it worked and what they need and if we could do it; and expand from there then. 
Risk management is, as can be seen, a complex matter centred on creating as safe a base as possible to assess the viability of the proposal, to identify and iron out problems, and to attract broader community interest in the scheme.

\subsection{Engaging the local community}

In addition to the proposed visioning day, the effort to attract broad community interest in the online shop was also a matter for technical discussion. The issues here were to do with reflecting the local character of the online shop as a feature of the shop itself, and were manifest in two particular ways. One, by displaying the locality of goods sold through the online shop, and two, by reflecting the local economic benefit accrued through use of the shop. It was projected that the first of these issues could be addressed by labelling products with different categories of 'localness' - e.g. that a product was grown or made locally. The second pillar of engagement involved representing the value of consumer spending to the local economy:

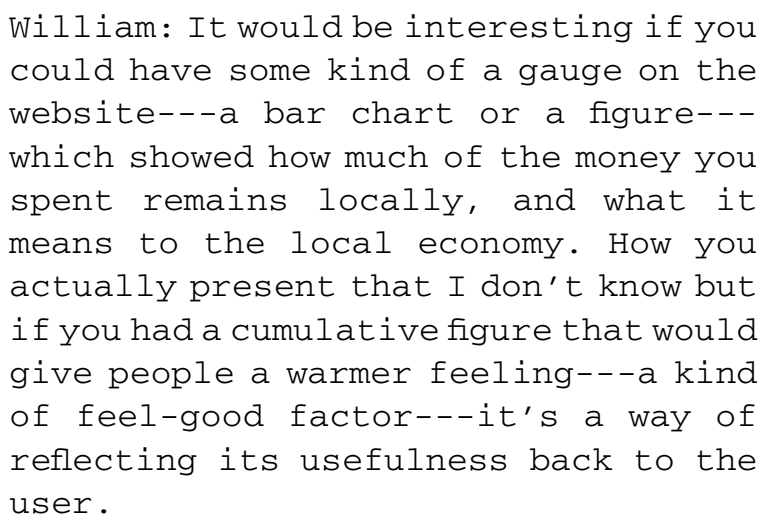

Both methods were considered to be important ways of engaging the local community with the online shop, with the latter in particular conveying a concrete sense that customers would be 'doing something useful and beneficial to society'.

\section{What's keeping the roof up?}

In the course of describing our methodological orientation to this particular study, we said that we are interested in understanding the 'work to make technology work' as this is 'what keeps the roof on' the online shop-what holds the enterprise up and drives the adoption of technology. No technology is reported in this study, and the reader might wonder what it is all about? We would point out, however, that just like a physical building, the roof goes on last, the walls before it, and both are built on top of the foundations. Our study of the occasioning of a local online cooperative shop makes those foundations visible. In doing so it reveals a host of organisational issues that shape and drive the online shop and inevitably hold it up.

In elaborating our methodological orientation, we said that we wanted to understand the invisible work that technology adoption turns upon. Our study reveals a distinct body of work involved in the occasioning of the online shop, which is occupied with the specification and configuration of an enterprise model the technology will have to support. The technology is subservient to this specification and configuration, while the technology figures in the board members' talk it is not the primary object of members' reasoning. Before its precise workings are considered, it is clearly essential to first give shape and form to the specific enterprise the technology is to support. Doing this is demonstrably a complex and challenging task that requires multiple organisational considerations be taken into account as is visible in the board members' talk.

The board members' talk instructs us in detail that specifying and configuring the enterprise model turns upon a host of organisational 'things' - defining the scope and function of the enterprise, coordinating delivery and supply, calculating costs, identifying risks, developing risk management strategies, and specifying ways and means of engaging the customer. These organisational matters are, of course, of broad concern-it is hard to imagine an enterprise that would not have to contend with them if it were to have any hope of success-but what interests us here is how these are themselves informed and shaped by an underlying concern with sustainability, which the online shop is ultimately accountable to.

Sustainability has become an important topic within systems design over recent years, even spawning a dedicated field called 'sustainable HCI'. When we consult this literature, it is clear that the concerns of rural enterprise with sustainability (cooperative or not) are not well represented. DiSalvo et al's [8] review of the field, for example, draws a picture in which sustainability revolves around technologically driven interests in exploiting sensing technologies to persuade people to adopt sustainable behaviours - to underscore the point, of their review of over 150 papers in the field over $90 \%$ were about 'persuasive technology', 'ambient awareness' and 'pervasive sensing'.

It might be argued that while sustainability is of broad interest in systems design, the current focus is rather narrow in scope (but not ambition). Where enterprise does figure in the literature, then it is largely as a problem rather than a solution, as a key driver of our carbon and broader ecological 'footprints'. The burden of effort in design would appear to be to leverage sensing technologies to make us aware of the impact of this, rather than to 'revision consumption', which as Goodman [12] tells us 'is a distinctly minority approach' within sustainable HCI and 
design more generally. Our study of $4 \mathrm{CG}$ is a study in this neglected area of sustainability. We believe it is an important area despite its current 'minority' status. The contribution of the rural economy to UK GDP, for example, was $£ 211$ billion in 2013 [22], some $40 \%$ more than the much-vaunted financial services sector. This sector is key to 're-visioning consumption' and reshaping our ecological footprints, and our study of 4CG provides us with a rare insight into some key issues on which this turns.

\subsection{Locality}

Re-visioning consumption demonstrably turns for 4CG on understanding locality. The local plays out in two distinct respects: it is both the topic of sustainability and the resource for bringing it about. Thus, sustainability is aimed at improving the local economy by developing the local economy. The local is not a matter of branding, but the very locus of efforts to re-vision consumption. The effort clearly trades on a contested and contestable rhetoric of what is and is not local. Settling the matter is not straightforward, but is contingent, plastic, open to revision. It can include the global, but it only insofar as it delivers demonstrable value 'here' to 'us'. Reworking the relationship between the global and the local is, then, key to revisioning consumption.

\subsection{Strategy}

The reworking is performed in terms of formulating future strategies for reconfiguring both the global and the parochial to add (or extract) local value. There is no single strategy, rather a multiplicity vie alongside and with one another. Strategies compete, they are accepted, rejected, put on hold, and picked up again. They are worked up with respect to what is known about the global and the parochial and how they might be leveraged to best advantage 'here', for 'us'. They are also worked up with respect to what is known about enterprise, about how business ticks and what needs to be done to make it tick. The re-visioning of consumption is not a fundamental re-visioning of business but how business might be done.

\subsection{Expertise}

Re-visioning consumption turns, then, upon expertise. Local expertise and with it an understanding of just what can be leveraged locally to add value to the global and the parochial. Strategic reasoning to rework the relationship between the two and formulate new local configurations of enterprise. And business acumen to ensure that forwardlooking strategies offer a realistic prospect of delivering the anticipated local value. The requisite expertise is not uniform in nature but manifold and many layered, marrying different perspectives on the local, the strategic, and enterprise together to develop a rounded and coherent revisioning of consumption that delineates the stakeholders, their relationships and the value chains between them.

\subsection{Engagement}

Re-visioning consumption also turns upon community engagement. This is not only a matter 'testing the water' and 'managing risk'. It is about building the local community and creating the context within which the necessary local reconfiguration can occur. It is about reaching out, making contact, sounding out, involving, and building momentum. It is perhaps the most difficult part of the mix, the most unpredictable, the most whimsical: the interest might be there, but actually turning people around is no easy matter. The lesson from $4 \mathrm{CG}$ is that it takes time, that engagement is an ongoing matter and that it is multifaceted and always oriented towards engendering the community with a stake in re-visioning exercises and a sense of ownership.

\subsection{Sustainability first}

Unlike sustainability in HCI, technology is not the driver in re-envisioning consumption. The driver is sustainability, and not sustainability in general, not sustainability as a global problem that we all need to be aware of and do something about, but sustainability as a local concern, as something that preoccupies 'just us', 'just here'. The reconfigurations that are required to sustain consumption locally are what drive consumption's re-visioning, not technological concerns. Technology is subservient to the local. Its role is subsequent and partial, but one of the Web of means for reconfiguring global and parochial relationships, just part of the enterprise model required to add local value.

\section{Conclusion}

We have presented a study of the occasioning of an online shop, which is intended to add value to the local economy of small market town in rural Wales. We appreciate the ready way in which a single study of a small rural enterprise in the back of beyond might be dismissed. It is worth noting in conclusion then that 4CG was the overall winner of Towns Alive 2013 [3]. The award was premised on 4CG's regeneration of Cardigan's local economy, and it brings with it broader recognition of the exemplary nature of its work. We are not merely recounting tales from the boondocks then. In exploring 4CG's turn to technology as 
another means of enhancing the rural economy, we begged the methodological question, 'what keeps the roof on the online shop' in a bid to understand the invisible work involved in constructing the technology and putting it to use. Inspecting the work elaborates what drives the adoption of technology in this context and the organisational issues which shape it. These issues are of broad relevance to parties who would turn to online shops to support rural economies. They point to the importance of defining (a) the scope and function of the enterprise, (b) delivery and supply coordination, (c) costs, (d) risks and risk management strategies, and (e) specific ways and means of engaging the local customer-base. Perhaps more significant, however, are the broader social and economic concerns that drive and shape the definition of these organisational issues, which put a much neglected area of sustainability centre stage: the collaborative 're-visioning of consumption'-reconfiguring the relationship between the global and the parochial, reshaping the ecological footprint, and adding even greater value to local enterprise and the communities it operates within than is achieved by merely moving online. In this respect, our study of $4 \mathrm{CG}$ opens up the re-visioning of consumption as an important research topic and investigation of its collaborative characteristics as key to understanding and driving broader sustainability agendas in systems development and society at large. Note: Since this paper was written, the software that was developed by the University of Nottingham was handed over to the social enterprise concerned, and a website is currently under development and being implemented to host the service.

Acknowledgments The research on which this article is based is funded by RCUK research grants Scaling the Rural Enterprise EP/ J000604/1 and Horizon EP/G065802/1. We would also like to thank $4 \mathrm{CG}$ for their ongoing support and input throughout the life of project. For an overview of 4CG please visit-https://youtu.be/ 5iNaud6AVKw.

Open Access This article is distributed under the terms of the Creative Commons Attribution 4.0 International License (http://crea tivecommons.org/licenses/by/4.0/), which permits unrestricted use, distribution, and reproduction in any medium, provided you give appropriate credit to the original author(s) and the source, provide a link to the Creative Commons license, and indicate if changes were made.

\section{References}

1. 4CG www.4cg.org.uk. Accessed 02 Feb 2015

2. Anderson R, Hughes J, Sharrock W (1989) Working for profit: the social organisation of calculation in an entrepreneurial firm. Aldershot, Avebury

3. BBC (2013) Cardigan's 4CG wins Towns Alive Award. www. bbc.co.uk/news/uk-wales-mid-wales-24955656. Accessed $02 \mathrm{Feb}$ 2015
4. Chamberlain A, Crabtree A, Davies M (2013) Community engagement for research. In: Proceedings of the 6th international conference on communities and technologies. ACM, Munich, pp 131-139

5. Charity Commission (2015) Industrial and provident societies. www.charitycommission.gov.uk/detailed-guidance/registering-acharity/exempt-charities-cc23/. Accessed 02 Feb 2015

6. Co-operatives UK (2015) Global co-operative sector. www.uk. coop/worldwide. Accessed 02 Feb 20115

7. Crabtree A, Chamberlain A (2014) Making IT pay a bit better. In: Proceedings of the 18th ACM conference on computer supported cooperative work. ACM, Baltimore, pp 687-696

8. DiSalvo C, Sengers P, Brynjarsdóttir H (2010) Mapping the landscape of sustainable HCI. In: Proceedings of the SIGCHI conference on human factors in computing systems. ACM, Atlanta, pp 1975-1984

9. Garfinkel H (1967) Studies in ethnomethodology. Prentice-Hall, Englewood Cliffs

10. Garfinkel H (ed) (1986) "Introduction”. In: Ethnomethodological studies of work. Routledge, London, pp 6-7

11. Garfinkel H, Wieder L (1992) Two incommensurable asymmetrically alternate technologies of social analysis. In: Watson G, Seiler SM (eds) Text in context: contributions to ethnomethodology. Sage, London, pp 175-206

12. Goodman E (2009) Three environmental discourses in humancomputer interaction. In: Proceedings of the SIGCHI conference on human factors in computing systems (extended abstracts). ACM, Boston, pp 2535-2544

13. Harper R, Hughes J (1993) What a f-ing system! Send 'em all to the same place then expect us to stop 'em hitting. Making technology work in air traffic control. In: Button G (ed) Technology in working order. Routledge, London, pp 127-144

14. HMRC (2015) industrial and provident societies. www.hmrc.gov. uk/manuals/ctmanual/ctm40505.htm. Accessed 02 Feb 2015

15. HM Treasury (2015) Industrial and provident societies: growth through co-operation. www.gov.uk/government/consultations/ industrial-and-provident-societies-growth-through-cooperation/ industrial-and-provident-societies-growth-through-co-operation. Accessed 02 Feb 2015

16. IBM (2013) Buying Local Will Beat Online, www.research.ibm. com/cognitive-computing/machine-learning-applications/retailstores.shtml [Accessed 02-15-15]

17. Lynch M (1993) Molecular sociology. In: Scientific practice and ordinary action. Cambridge University Press, Cambridge, pp 203-264

18. National Archive (2015) Industrial and Provident Societies Act 1965. www.legislation.gov.uk/ukpga/1965/12/contents. Accessed 02 Feb 2015

19. Pollner M (1987) Mundane reason: reality in everyday and sociological discourse. Cambridge University Press, Cambridge

20. Sacks H, Schegloff E, Jefferson G (1974) A simplest systematics for turn-taking in conversation. Language 50(4):696-735

21. Suchman L (1994) Working relations of technology production and use. Computer supported cooperative work: the journal of collaborative computing 2(1-2):21-39

22. Phillipson J, Turner R (2013) Rural areas as engines of economic growth. Policy and Practice Notes No. 41. Centre for Rural Economy, Newcastle University

23. Zimmerman D, Pollner M (1970) The everyday world as a phenomenon. In: Douglas J (ed) Understanding everyday life: towards the reconstruction of sociological knowledge. Aldine Publishing, Chicago, pp 80-103 